\title{
Экспертиза
}

ИВАНОВ Олег Борисович - руководитель Центра урегулирования социальных конфликтов (129063, Россия, г. Москва, nр-кт Мира, 72, оф. 2107; sovetmoто@таil.ru)

ИЛЬИНСКАЯ Юлия Игоревна - исполнительный директор Центра урегулирования социальных конфликтов (129063, Россия, г. Москва, пр-кт Мира, 72, оф. 2107; yulia.ilinskaya@gmail.com)

\section{ПЕРСПЕКТИВЫ ИНСТИТУТА МЕДИАЦИИ В УРЕГУЛИРОВАНИИ ГРАДОСТРОИТЕЛЬНЫХ КОНФЛИКТОВ В РОССИИ}

Аннотация. В статье рассматриваются градостроительные конфликты современной России, возможность эффективного управления ими с помощью медиации. Авторы опираются на самостоятельно собранный богатый практический материал: мнения экспертов, участников градостроительных конфликтов, конфликтологов, государственных служащих. Делается вывод о целесообразности применения медиации как эффективного инструмента разрешения градостроительных конфликтов, затрагивающих большое число участников, имеющих общественный резонанс и объективно сложносоставных с точки зрения управления и разрешения.

Ключевые слова: градостроительные конфликты, медиация, городское пространство, урбанизация, город, мегаполис, застройка, дегуманизация

\footnotetext{
овременная Россия формировалась (и продолжает формироваться) на фоне серьезных социально-экономических, политических, культурных и отчасти даже цивилизационных потрясений, затронувших основы общественной жизни. Сфера градостроительства также претерпела существенные изменения, причем в ней внедрение рыночных форм взаимодействия происходит наиболее конфликтно. Исследователи нередко отмечают, что причиной проблем современных городов является градостроительная политика с ее ошибочной, ущербной организацией социального пространства [Мезенцев 2010: 390]. Пространство городов становится объектом интересов девелоперов, которые, опираясь на поддержку властей разного уровня, запускают механизмы трансформации городского пространства, зачастую не учитывая мнения горожан, которые вынуждены самоорганизовываться для защиты своих интересов. Все это порождает новые отношения социального неравенства в городах [Тыканова, Хохлова 2015: 246].

Проблема применения инновационных подходов к разрешению градостроительных конфликтов в современных российских условиях приобретает очевидную актуальность. К таким подходам относят и медиацию, основная задача которой видится в первую очередь в том, чтобы исчерпать конфликт путем его урегулирования за счет выявления истинных интересов сторон конфликта. При этом медиация для градостроительных конфликтов в современной России применяется крайне редко. Это объясняется относительной новизной самого правового и организационного механизма, настороженное и зачастую предвзятое отношение к медиации со стороны участников конфликта.

Исследуя возможность и перспективы практического применения медиации в современных длящихся градостроительных конфликтах, авторы статьи путем экспресс-анкетирования опросили участников актуальных столичных градостроительных конфликтов: представителей инициативных групп, архитекторов, активистов, госслужащих, конфликтологов и медиаторов. Авторов статьи интересовало отношение анкетируемых как к градостроительным конфликтам вообще, так и к перспективам применения медиации как способа их урегулирования.
} 
В рамках проведенного исследования были опрошены следующие практикующие специалисты и участники конфликтов: Л. Цой, руководитель Московской школы конфликтологии, кандидат социологических наук, конфликтолог; O. Иванов, руководитель Центра урегулирования социальных конфликтов, заслуженный юрист Московской области, медиатор; $A$. Козлов, глава общественного штаба по контролю за реализацией программы реновации Общественной палаты города Москвы; В. Кормаков, генеральный директор ООО «Стройкапитал», застройщик в городе Старая Купавна, жилой комплекс «Купавино» (конфликт, связанный с длительной просрочкой сдачи дома в эксплуатацию); Ю. Шубин, член движения «Сорок сороков», активист, выступающий за строительство храма в парке «Торфянка» (г. Москва); Н. Федорова, муниципальный депутат Лосиноостровского муниципального округа, г. Москва, противник строительства храма в парке «Торфянка»; С. Разворотнева, первый заместитель председателя комиссии по ЖКХ, строительству и дорогам Общественной палаты РФ, исполнительный директор Национального центра общественного контроля в сфере ЖКХ «ЖКХ Контроль»; $А$. Ткачук, заместитель руководителя мастерской архитектурно-градостроительного проектирования ГАУ «Институт генплана Москвы»; E. Соседов, глава московского областного отделения Всероссийского общества охраны памятников истории и культуры.

Обработка полученного массива эмпирических данных позволила сделать ряд выводов, касающихся потенциала применения медиации в градостроительных конфликтах. Экспертные мнения при их анализе были разделены на три группы: это причины градостроительных конфликтов в современной России, проблемы коммуникации субъектов градостроительных конфликтов, перспективы применения медиации при разрешении таких конфликтов.

\section{Причины градостроительных конфликтов в современной России}

Рассуждая о причинах градостроительных конфликтов в современной России, Л. Цой справедливо указывает: «Будущее любого современного города связано с его развитием. Представление же о том, как и в каком направлении должен развиваться конкретный город, - оно у разных членов локального сообщества разное. Именно поэтому город представляет собой пространство столкновения интересов, противодействия сторон и конфликтов». Эта позиция представляется достаточно обоснованной, хотя, с другой стороны, каждый случай следует рассматривать отдельно, исходя из его специфики.

С. Разворотнева говорит и о такой причине: «Сейчас градостроительные конфликты являются одними из самых частых. Это, например, конфликты, связанные с уплотнительной застройкой, обманутыми дольщиками, с согласованием расположения различных схем транспортной инфраструктуры, особенно когда речь идет, например, о строительстве крупных дорог через жилые массивы. В соответствии с градостроительным законодательством люди должны такие планы обсуждать и согласовывать, но на практике те, кого эти изменения касаются непосредственно, - они всегда выступают против. Понятно, что городу объективно нужна эта дорога, но никому не хочется быть теми, за счет кого эти городские проблемы решаются. Поэтому в градостроительных конфликтах часто частные интересы борются с интересами широкой общественности».

В целом респонденты (за исключением специалистов-конфликтологов и медиаторов) склонны рассуждать о причинах градостроительных конфликтов (как вообще, так и конкретно того конфликта, в котором они участвуют), оперируя достаточно общими утверждениями и понятиями, что косвенно подтверждает отсутствие требуемого уровня рефлексии. Прозвучавшие причины 
сводятся к тому, что одна из сторон (застройщик, оппонент, власть и т.п.) либо обманывает другую (локальное сообщество или его часть), либо просто не желает учитывать очевидные (для стороны) интересы.

Так, рассуждая о конфликте вокруг строительства храма в парке «Торфянка», Ю. Шубин подчеркивает, что причины этого конфликта носят субъективноидеологический характер, поскольку, с одной стороны, «разве какой-то человек будет протестовать против строительства храма, даже если он не христианин», а с другой стороны, по его утверждению, позиция противников строительства профинансирована извне России, и их действия являются лишь одним из звеньев борьбы внешних сил, перед которыми стоит задача уничтожения российской государственности. А Н. Федорова, представляющая иную сторону этого конфликта, заявляет: «...я переехала в этот район десять лет назад, чтобы жить около этого парка, - тут такая чудесная зелень, соловьи, я подумала, что хочу тут жить; в первую очередь я за сохранение природы». Участники конфликта, обсуждая одну и ту же проблему, говорят будто на разных языках.

\section{Актуальные проблемы коммуникации субъектов градостроительных конфликтов}

Л. Цой особо подчеркивает важность выстраивания коммуникации между участниками (субъектами) градостроительного конфликта: «Важно, чтобы город не превратился в арену хронических конфликтов. Для этого нужны как культура диалога, так и понятная всем процедура согласования основных позиций градостроительства. В современной России эти факторы недостаточно развиты».

Это важный момент, весьма красноречиво, как мне кажется, иллюстрирующий степень заинтересованности органов власти в управлении градостроительными конфликтами. А. Ткачук так описывает сложившуюся ситуацию: «В рамках работы нашего института сегодня не практикуются мероприятия по коммуникации с жителями, хотя это было бы, наверное, интересно и полезно - проводить такие предварительные встречи, выслушивать мнения, которые могут повлиять на принимаемые управленческие решения». При этом она справедливо отмечает, что «никто не хочет получить негативный резонанс, критику со стороны жителей». В похожем ключе выступает Е. Соседов: «У нас (активная фаза конфликта вокруг «Мортонграда». - Прим. авт.) постоянно проводились митинги и народные сходы, их эффективность безусловно была. Мы видели, что публичное выражение позиции населения очень болезненно воспринимается другой стороной. Проведение таких публичных мероприятий может в корне изменить ситуацию». С. Разворотнева добавляет: «Площадки общественных советов и региональных общественных палат часто становятся такими коммуникативными площадками для обсуждения градостроительных конфликтов. Там, где их нет, конфликт часто выливается в митинги и забастовки».

Взаимоисключающие позиции экспертов по конфликту вокруг строительства храма в парке «Торфянка», их более чем спорные и субъективные аргументы в пользу своих сторон также демонстрируют отсутствие сколько-нибудь выстроенной коммуникации между субъектами конфликта и, что существенно опаснее, отсутствие желания такую коммуникацию выстраивать. Таким образом, коммуникация заменяется теорией заговора, огульной демонизацией оппонента и утратой даже теоретической возможности поиска компромисса. В такой ситуации управлять конфликтом крайне сложно, в нем полностью аннигилируется любое рациональное начало.

С другой стороны, нельзя не согласиться с Н. Федоровой, которая утверждает: «Если бы на предварительном этапе прошли полноценные публичные слуша- 
ния, то ситуация развивалась бы совсем по-другому, было бы видно, что люди против строительства храма. Даже если бы власти решились строить, то люди стали бы писать во все инстанции, и это не привело бы ни к чему хорошему. То есть, на начальном этапе противостояния еще вполне возможен был бы диалог, люди не были доведены до такого состояния обиды на то, что произошло. Мы ведь стучали в самые разные двери, просили поговорить с нами, но из всех органов мы получали идентичные письма - предложение в предложение, под копирку».

А. Козлов также подчеркивает важность коммуникации и то обстоятельство, что общественный штаб по контролю за реализацией программы реновации при Общественной палате города Москвы как раз и создан в качестве одной из площадок, обеспечивающих подобную коммуникацию. Так, он отмечает, что с момента запуска программы реновации в штаб обращались как сторонники, так и противники идеи: «Обращения в штаб по характеру меняются в зависимости от конкретного этапа программы. Сейчас большая часть обращений поступает от участников программы, вопросы ориентированы на стартовые площадки, очередность домов, сроки, отделку квартир, дополнительную покупку квадратных метров жилой площади, как будет учитываться социальная, транспортная и иная инфраструктура. Иногда спрашивают, как выйти из программы, иногда - как войти. Обращаются к нам и противники, мы их не игнорируем, воспринимаем их обращения нормально. С теми из них, с кем можно адекватно разговаривать, мы готовы вести диалог, суммировать их позиции и доносить их до действующей власти».

Нередко стороны конфликта общаются не напрямую, а через средства массовой информации. Таким образом создается лишь иллюзия коммуникации, которая, очевидно, ничуть не лучше, чем полное отсутствие коммуникации, а в чем-то даже и опаснее с точки зрения управляемости конкретного конфликта. Так, например, Е. Соседов, комментируя конфликт вокруг «Мортонграда», отмечает: «Мы писали обращения в адрес собственника, однако никаких ответов от него так и не получили. Были их ответы журналистам, интервью, статьи, но на диалог с жителями собственник не идет».

Приведенные позиции экспертного сообщества позволяют сделать однозначный вывод: система коммуникации в рамках градостроительного процесса в столице не отлажена, даже несмотря на то, что ее необходимость признается на уровне экспертного сообщества. Между тем выстраивание эффективных коммуникативных схем между всеми участниками конфликтного процесса является ключевым понятием в управлении конфликтом и в медиативных процедурах. Существующий в настоящее время фактор недоверия властям весьма ярко проявляется в т.Ч. и в градостроительных конфликтах, и во многом из-за пассивной позиции самих властей в вопросах выстраивания эффективных средств коммуникации с локальным сообществом.

\section{Возможность и перспективы применения медиации}

\section{при управлении градостроительными конфликтами и их разрешении}

Рассуждая о перспективах применения медиации при управлении градостроительными конфликтами и их разрешении, Л. Цой подчеркивает: «В современной России, с ее неустоявшимися, только формируемыми механизмами общественной коммуникации, на первую роль выходят технологии управления и разрешения градостроительных конфликтов, в том числе и медиация». В плане работы медиатора в поле градостроительного конфликта Л. Цой указывает на две концептуальные задачи: во-первых, определить «выпавшее» из поля зрения проектировщиков существенное основание принятия проектного реше- 
ния и, во-вторых, создать механизм или предложить процедуру для включения этого основания в проектирование. В то же время, по мнению респондента, на сегодняшний день российское общество крайне недоверчиво относится к медиаторам, а стороны градостроительного конфликта склонны не признавать авторитет медиатора, его профессиональные и репутационные компетенции, его лояльность, объективность и независимость. Это вызвано спецификой института и относительно небольшой практикой его применения.

Похожую позицию занимает и Ю. Шубин. Он подчеркивает, что знаком с понятием медиации и считает потенциал этого института достаточно существенным, однако подчеркивает, что, по его мнению, в конфликте вокруг строительства храма в парке «Торфянка» одна из сторон обманывает другую. В этой связи функции медиатора он воспринимает весьма специфически - в соответствии со своей установкой. То есть, для него медиатор должен быть не специалистом, который сближает позиции сторон конфликта, а неким третейским судьей, который либо подтвердит его как стороны конфликта очевидную (для него) правоту, либо будет обвинен в том, что «он повелся на ложь». Несколько анекдотичным выглядит то, что сам респондент, выступая с таких радикальных и бескомпромиссных позиций, в то же время заявляет следующее: «Должна быть поэтапность, чтобы они приводили свои доказательства, а мы - свои. Совсем радикалы не пойдут на компромисс, они будут выведены на чистую воду и уйдут, останутся только местные жители, и они сами по себе уйдут в нейтральную позицию. С оппонентами невозможно договориться, а сами жители ничего не решают».

Его позицию разделяет и Н. Федорова: «Точно ли медиатор не будет заинтересован по отношению к одной или другой стороне? Это важно, потому что доверие сильно подорвано. Особенно по отношению к государству». При этом сама идея привлечения к урегулированию конфликта медиатора респондентом воспринимается весьма позитивно, хотя из приведенной цитаты очевидно, что медиатор воспринимается не как независимое лицо, а как чей-то инструмент. Респонденты в массе своей крайне настороженно относятся к самой идее независимости медиатора: в теоретическом плане они с ней полностью солидарны, но почти всегда оговариваются, что на практике достичь такой независимости невозможно и, следовательно, задача сторон в этой связи представляется не как помощь медиатору в поиске компромисса, а как «перетягивание» медиатора на свою сторону. Следует отметить, что с этой позиции многие респонденты неосознанно наделяют медиатора статусом своего рода общественного арбитра, имеющего какие-то полномочия на принятие (или хотя бы лоббирование) того или иного решения, причем это наделение происходит у сторон автоматически. Это также иллюстрирует тот факт, что понятие медиации совершенно не закреплено в общественном сознании, даже у тех людей, которые знакомы с ним как с термином.

О. Иванов, в целом поддерживая идею применения медиации в градостроительных конфликтах, справедливо указывает на объективные трудности такого применения, связанные не в последнюю очередь с несовершенством имеющейся законодательной базы: «Следует учесть, что медиаторы осуществляют свою деятельность в соответствии с соответствующим федеральным законом и, следовательно, объективно ограничены этим законом. При этом предмет регулирования федерального закона и сфера его действия сформулированы таким образом, что с правовой точки зрения возможность использования процедуры медиации в градостроительных конфликтах - конфликтах публичных, затрагивающих большое количество людей, - нуждается в очевидном уточнении». Еще одной чисто правовой проблемой, по мнению респондента, является 
прямой законодательный запрет на оказание медиатором любой стороне конфликта юридической, консультационной или любой иной помощи. Очевидно, что такой запрет носит явно избыточный характер и не соответствует логике медиации, целям и задачам эффективного разрешения градостроительного конфликта. Юридически грамотно составленные документы усиливают влияние достигнутых между сторонами конфликта в процессе его разрешения договоренностей. Более того, любой градостроительный конфликт всегда имеет и правовую составляющую, и, следовательно, эффективно разрешить его, не прибегая к нормам права, невозможно. Актуальной остается и проблема принудительного исполнения медиативного соглашения. Действующее законодательство такую возможность исключает кроме случаев, когда суд своим решением придает медиативному соглашению силу мирового. Однако к градостроительным конфликтам такая практика почти всегда неприменима, и это обстоятельство объективно снижает число обращений к медиации на этапе выбора способа урегулирования спора. Говоря о сложностях, с которыми может столкнуться применение медиации в градостроительных конфликтах, О. Иванов справедливо указывает также на отсутствие средств для оплаты труда медиаторов или же, обозначая эту проблему шире, спорное (с точки зрения участников градостроительного конфликта) соотношение между ценой услуг медиатора и тем результатом, который будет получен по итогам его работы.

К слову, в вопросе оплаты труда Л. Цой вступает в заочный спор с О. Ивановым и указывает, что медиация в современной России, как и любой относительно новый социальный институт, испытывает объективные проблемы становления и развития и в связи с этим - определенный кризис доверия со стороны потенциальных и заинтересованных в нем пользователей. Этот кризис, по мнению Л. Цой, можно преодолеть путем активного участия медиаторов в урегулировании градостроительных конфликтов. В том числе это следует делать на безвозмездной основе - как нарабатывая положительный опыт медиации, так и повышая авторитет этого института в общественном восприятии в целом.

А. Козлов подчеркивает, что в его деятельности еще не было опыта применения медиации, он в целом полагает привлечение медиаторов к градостроительным конфликтам полезным и здравым начинанием, справедливо уточняя: «Для медиации необходимо желание двух сторон найти какое-то общее решение. Но бывает так, что у противников есть эмоции, с одной стороны, и нет желаний искать компромиссы - с другой. Хотя, в целом, по моему опыту, все-таки большинство участников градостроительных конфликтов склонны искать компромиссы. Это обстоятельство позволяет использовать медиационные технологии». Этой же позиции придерживается и Е. Соседов: «Медиация имеет смысл, когда есть базовые установки у обеих сторон. Мы понимаем тоже, что жители не идеальные и общественность не идеальная, могут палку перегибать где-то. Смысл есть тогда, когда и одна и другая сторона готовы друг друга слышать, уважительно относиться к позиции друг друга и действовать в рамках закона. Если одна из сторон не готова слышать и поступиться какими-то своими интересами для достижения какого-то компромисса и действовать в рамках закона, то услуги медиаторов будут бессмысленны».

С. Разворотнева, говоря о преимуществах медиации в градостроительных конфликтах, подчеркивает: «Я хорошо отношусь к медиации и полагаю, что при строительстве крупных объектов медиаторы должны помогать находить общий язык всем заинтересованным лицам. Часто городское сообщество вообще не умеет разговаривать с застройщиками и находить взаимоприемлемые варианты. Когда затронуты интересы большого числа участников - застройщиков, администрации города, людей, проживающих в непосредственной близости 
от объекта строительства, людей, проживающих в городе вообще, нужно проводить сложные переговоры, нужно максимально учитывать всю эту паутину факторов. Понятно, что человек без специальной подготовки с задачей такой сложности не справится».

С другой стороны, применение медиации при специфических градостроительных конфликтах (как, например, в случае с обманутыми дольщиками ЖК «Купавино) может быть недостаточно эффективным. Об этом говорит В. Кормаков, который подчеркивает, что с местной администрацией у застройщика (который находится в состоянии банкротства) «нормальные, рабочие отношения», как и с дольщиками, «если общаться с ними поодиночке». С ним можно согласиться отчасти, поскольку градостроительные конфликты, связанные с несвоевременной сдачей строящегося жилья в эксплуатацию, должны быть разрешены не путем поиска компромиссов в широком смысле этого слова, а путем выполнения ранее взятых на себя обязательств застройщиком. Здесь компромисс возможен только в сроках сдачи объекта, но не в каких-то иных условиях его сдачи, и, следовательно, речь должна идти о соблюдении таких обязательств и о юридической ответственности за их несоблюдение.

Мнение опрошенных сводится к тому, что медиация может и должна использоваться при управлении градостроительными конфликтами и что сама эта конфликтная сфера вполне готова к внедрению медиации. В то же время опрошенные лица слабо проинформированы о медиации как об относительно новом институте управления конфликтами вообще и о возможности ее применения в специфических градостроительных конфликтах в частности. Опрошенные эксперты утверждают, что медиация имеет существенные преимущества перед традиционными формами урегулирования конфликтов вообе и конфликтов градостроительных в частности. Самое важное: медиация позволяет выявить истинные интересы участников конфликта, сформулировать их. Это позволяет запустить процесс выявления принципиальных и факультативных различий интересов участников конфликта, определить их возможные общности и через все описанные механизмы создать для участников конфликта необходимые формы взаимоотношений, которые способствовали бы трансформации конфронтации во взаимовыгодное сотрудничество, построенное на позитивных началах. Медиация всегда исходит из того, что какими бы непреодолимыми ни казались существующие противоречия между сторонами конфликта, у них существует реальная возможность сохранить партнерские отношения и найти актуальные формы совместной деятельности. Именно такой позитивистский подход выгодно отделяет медиацию от традиционных способов разрешения конфликта, которые в ряде случаев в силу ограниченности своего функционала не могут снять остроту вопроса в принципе, поскольку изначально преследуют иные цели.

В то же время нельзя не согласиться с мнением С. Разворотневой: «Медиация у нас развивается медленно, потому что граждане слишком слабы, альтернативные гражданские группы слишком слабы и, в конченом счете, сильные давят слабых. Развитие гражданского общества и усиление давления влиятельных, активных групп граждан, вовлекаемых в градостроительные конфликты, усилит необходимость проведения переговоров и востребованность медиации как одного из ключевых инструментов управления градостроительным конфликТОМ».

Резюмируя вышеизложенное, следует отметить, что идеальная схема взаимодействия, минимизирующая саму возможность возникновения и развития градостроительного конфликта, подразумевает непосредственную связь каждого с каждым. Однако такая система объективно крайне сложна для практической 
реализации и в современной России попросту не обеспечена нормативно-правовыми документами и организационными структурами. В настоящее время в городах власть взаимодействует с участниками городского сообщества опосредованно - через представителей групп интересов, которые зачастую имеют собственные интересы, не всегда совпадающие с интересами населения. Такая система, безусловно, требует создания надежных коммуникационных связей, обеспечивающих устойчивость входящих в них участников [Макаренков 2014: 76]. В современной же России институт цивилизованного диалога между участниками градостроительных конфликтов находится в зачаточном состоянии, что приводит к ситуации, в которой каждая сторона отстаивает исключительно свои интересы и не рассматривает вариант сколько-нибудь существенных уступок, что, в свою очередь, не позволяет создать платформу для формирования общественного согласия [Юханова 2014: 56].

Так как же избежать градостроительного конфликта? Лучше всего необходимые условия для этого сформулировал крупный российский ученый Вячеслав Глазычев в одном из своих интервью: «Требуется осуществлять процесс городского планирования и проектирования на всех уровнях (от города в целом до квартала и сквера) в диалоговом режиме между администрацией, архитекторами и озабоченными горожанами. На практике же это весьма трудоемкая система процедур, требующая к тому же не только доброй воли, но и очень высокой квалификации ведущего в проектном процессе» 1 .

Преимущества медиации как формы урегулирования градостроительных конфликтов обусловлены тем, что именно медиация позволяет выявить истинные интересы участников конфликта, сформулировать их. Это, в свою очередь, позволяет запустить процесс выявления различий интересов участников конфликта, определить их потенциальные общие интересы и создать для участников конфликта приемлемые формы взаимоотношений, способствующие построению взаимовыгодного сотрудничества. Медиация принципиально исходит из того, что у сторон конфликта в любом существует возможность сохранить партнерские отношения и найти приемлемые формы совместной деятельности. Этот позитивистский подход выгодно отделяет медиацию от традиционных способов разрешения конфликта.

Медиация сегодня - все еще новелла для российского общества. Понимание сущности медиации как уникального способа разрешения еще недостаточно укоренилось не только в российском общественном сознании, но и среди представителей профессиональных групп [Тюльканов, Никитина, Геворкова 2016: 103]. Однако потенциал этой новеллы признается всеми участниками градостроительных конфликтов.

Некоторые из описанных проблем можно преодолеть силами экспертного сообщества. В частности, медиаторам следует активнее участвовать в урегулировании градостроительных конфликтов, в т.ч. и на безвозмездной основе. Это позволит, с одной стороны, наработать положительный опыт медиации, а с другой - повысить в общественном сознании авторитет этого института. В качестве организационных предложений, способных повысить востребованность медиации, разумно предложить формировать отраслевые медиативные центры, в т.ч. и с государственной поддержкой. Такие центры вполне могут стать «точками роста» интереса к медиации - как научного и просветительского, так и практического.

\footnotetext{
1 Глазычев В.Л. 2006. Семь шагов к городу будущего: интервью. - Официальный сайт Московской иколы конфликтологии. Доступ: http://conflictmanagement.ru/sem-shagov-k-gorodu-budushhego (проверено 05.05.2018).
} 


\title{
Список литературы
}

Макаренков Е.В. 2014. Развитие мегаполиса: общественное участие как политическая проблема. - Власть. № 12. С. 74-78.

Мезенцев С.Д. 2010. Современное градостроительство: должное и сущее, идеалы и реальность. - Вестник МГСУ. № 4-3. С. 389-393.

Тыканова Е.В., Хохлова А.М. 2015. Городской политический режим в СанктПетербурге: роль реальных и воображаемых «машин роста» в борьбе за городское пространство. - Журнал исследований социальной политики. № 2. С. 241256.

Тюльканов С.Л., Никитина И.Б., Геворкова К.В. 2016. Проблемы применения законодательства о медиации при организации и проведении процедуры медиации. - Современное право. № 7. С. 98-110.

Юханова Э.Т. 2014. Современные проблемы градостроительной политики в Нижнем Новгороде. - Власть. № 6. С. 55-58.

IVANOV Oleg Borisovich, Head of the Center for Settlement of Social Conflicts (of. 1207, 72 Mira Ave, Moscow, Russia, 129063; sovetmomo@mail.ru)

IL'INSKAYA Yuliya Igorevna, Executive Director of the Center for Settlement of Social Conflicts (of. 1207, 72 Mira Ave, Moscow, Russia, 129063; yulia.ilinskaya@gmail.com)

\section{PROSPECTS OF THE MEDIATION INSTITUTE IN THE ARRANGEMENT OF URBAN CONFLICTS IN RUSSIA}

\begin{abstract}
The article considers the phenomenon of urban conflicts in modern Russia, as well as the ability to solve them effectively through mediation procedures. The authors rely on independently collected rich practical material: the opinions of experts, participants in existing urban development conflicts, conflictologists, and public officials. The authors conclude about the possibility and expediency of using mediation as a potentially very effective tool for managing urban conflicts and their resolution. In preparing the article, the authors relied on the advantages of using institutional, systemic and sociological methods. The novelty of the work consists in an attempt to systematically consider, on the base of unique sociological data obtained, the possibility of applying the new institute of mediation with regard to the resolution of urban conflicts involving a large number of participants, having significant public resonance and, therefore, objectively complex in terms of arrangement and solution.
\end{abstract}

Keywords: urban conflicts, mediation, urban space, urbanization, city, metropolis, development, dehumanization 